\title{
Matérista
}

ISSN 1517-7076

Revista Matéria, v. 11, n. 2,pp. $70-87,2006$

http://www.materia.coppe.ufrj.br/sarra/artigos/artigo10698

\section{Modelamento Termodinâmico e Cinético por meio do Método Calphad do Processamento Térmico e Termoquímico de Aços}

\author{
C.M GARZÓN ${ }^{1}$; A.P. TSCHIPTSCHIN ${ }^{2}$ \\ ${ }^{1}$ Laboratório Nacional de Luz Síncrotron \\ Caixa Postal 6192 - CEP 13084-971, Campinas, SP, Brasil \\ e-mail: cmario@lnls.br \\ ${ }^{2}$ Escola Politécnica da Universidade de São Paulo \\ Av. Prof. Mello Moraes, 2463 - CEP 05508-900 - São Paulo, SP, Brasil \\ e-mail: antschip@usp.br
}

\begin{abstract}
RESUMO
Na década de 1970 Kaufman e Bernstein realizaram trabalho pioneiro sobre modelamento numérico da termodinâmica de sistemas multicomponentes e fundaram o grupo CALPHAD (Computer Coupling of Phase Diagrams and Thermochemistry), que tem como propósito promover a termodinâmica computacional e desenvolver programas computacionais para: (i) avaliar e validar dados experimentais (e teóricos) para incorporá-los às bases de dados auto-consistentes, (ii) representar as propriedades termodinâmicas de sistemas multicomponentes, (iii) modelar processos tecnológicos. Além de programas para modelamento termodinâmico, vários programas computacionais CALPHAD têm sido desenvolvidos, também, para calcular a cinética de transformações de fase controladas por difusão, os quais têm interfase com programas de calculo termodinâmico e com bases de dados de mobilidades atômicas. No presente trabalho relatam-se diferentes exemplos do uso do método CALPHAD para o modelamento matemático de diferentes processamentos térmicos e termoquímicos de aços, os quais correspondem a estudos de casos realizados no departamento de Engenharia Metalúrgica e de Materiais da Escola Politécnica da Universidade de São Paulo. Por meio de modelamento CALPHAD foi possível otimizar os parâmetros de processamento durante: a nitretação de aços de alta liga, o processamento térmico de aços TRIP, a produção de nitretos $\mathrm{CrN}_{\mathrm{N}} \mathrm{Cr}_{2} \mathrm{~N}$ a partir de pó de cromo, o tratamento térmico de solubilização de aços inoxidáveis e o tratamento térmico de decomposição de carbonetos em aços ferramenta.
\end{abstract}

Palavras chaves: CALPHAD, termodinâmica computacional, modelamento matemático, tratamentos térmicos.

\section{Thermodynamic and Kinetic Modeling of the Thermal and Thermochemical Processing of Steels Using the Calphad Method}

\section{ABSTRACT}

In 1970s, Kaufman and Bernstein summarized the general features of computer numerical calculation of multicomponent phase equilibrium thermodynamics, by means of polynomial expressions of the Gibbs free energy, and they created the CALPHAD group (Coupling of Phase Diagrams and Thermochemistry). CALPHAD group aims to promote computational thermodynamics through development of models to (i) critical assessment of experimental and computed data and their incorporation into selfconsistent databases, (ii) represent thermodynamic properties for various phases which permit prediction of properties of multicomponent systems, and (iii) development of software to improve understanding of various industrial and technological processes. Besides software for performing thermodynamic modeling, there are today several programs to modeling kinetics of diffusion controlled phase transformations. These kinetic programs are interfaced with programs for performing thermodynamic simulations as well as with kinetic databases. In this work, several case studies about numerical modeling of thermal as well as thermochemical processing of steels are reported. The analyzed case studies are brief descriptions of theoretical and experimental research works which are being carried out in the Metallurgical and Materials Engineering Department, University of São Paulo. It is shown the processing parameter optimization during: 
high-alloy steel nitriding, TRIP steel thermal processing, $\mathrm{CrN}$ and $\mathrm{Cr}_{2} \mathrm{~N}$ thermal synthesis from chromium powder, solution annealing of stainless steels, and primary-carbide decomposition during heat treatment of tool steels.

Keywords: CALPHAD, computational thermodynamics, numerical modeling, heat treatments.

\section{INTRODUÇÃO}

O modelamento matemático da estabilidade de fases e das transformações de fase em materiais de engenharia é uma importante ferramenta para o desenvolvimento ou otimização do seu processamento. Já no século XIX, o trabalho de Gibbs, no qual foram correlacionados os parâmetros termodinâmicos com a estabilidade das fases em sistemas multicomponentes, permitiu o modelamento analítico da estabilidade de fases, tanto para fins acadêmicos quanto para desenvolvimento tecnológico. No entanto, durante muitas décadas, a grande quantidade de parâmetros de ajuste (estimados experimentalmente) requerida, tornava esses modelos limitados para prever novas condições de processamento ou novas composições químicas.

Durante muitos anos uma das principais dificuldades para a expansão do modelamento matemático da termodinâmica de materiais foi a impossibilidade de execução de cálculos matemáticos extensos. Com o vertiginoso aumento da capacidade de cálculo, produto do desenvolvimento e aprimoramento dos computadores, tornou-se possível o modelamento termodinâmico de vários sistemas multicomponentes, sendo desenvolvidos algoritmos de cálculo baseados na minimização, por métodos numéricos, de expressões algébricas da energia livre de Gibbs. Kaufman e Bernstein realizaram trabalho pioneiro neste campo [1], fundando o grupo CALPHAD (Computer Coupling of Phase Diagrams and Thermochemistry). O objetivo do grupo CALPHAD é desenvolver programas de computador usando a termodinâmica computacional para: (i) representar as propriedades termodinâmicas de sistemas multicomponentes; (ii) avaliar e validar dados experimentais (e teóricos) para incorporá-los às bases de dados auto-consistentes, (iii) modelar processos tecnológicos. O acrônimo CALPHAD se refere hoje não só ao método de cálculo, mas também ao protocolo de construção das bases de dados, ao grupo de trabalho, ao congresso anual dos usuários do método e a um jornal cientifico. Este método, no entanto, não é a única técnica computacional para o modelamento termodinâmico e cinético dos materiais de engenharia, bem como de seu processamento. Há vários outros métodos baseados na termodinâmica estatística e na física quântica, podendo ser destacados: (i) o método dos primeiros princípios, cuja principal aplicação consiste em cálculos, a $0 \mathrm{~K}$, da energia de diferentes configurações atômicas e estruturas cristalinas; (ii) o método variacional de clusters, que encontra sua principal aplicação no modelamento da entropia de diferentes configurações atômicas e estruturas cristalinas; (iii) o método de Montecarlo, que pode ser usado tanto no cálculo de diagramas de fases como na simulação da cinética de transformações de fases; e (iv) o phase field method, que atualmente é usado principalmente no cálculo da cinética de transformações de fase. Em geral, tais métodos não são excludentes, observando-se excelentes resultados quando são feitas interações entre os mesmos. Por exemplo, a incorporação a alguns cálculos CALPHAD de energias de formação calculadas pelo método dos primeiros princípios ou o uso das energias de cluster em simulações de Montecarlo tem levado a excelentes resultados. Contudo, para o modelamento não só da estabilidade de fases como também da cinética de transformações de fase, o método CALPHAD está muito à frente dos outros no que diz respeito à capacidade de cálculo. Para diferentes sistemas termodinâmicos, muitos diagramas de equilíbrio têm sido modelados e otimizados através de bases de dados construídas conforme o protocolo CALPHAD. Em virtude do alto grau de amadurecimento deste método, já é possível o modelamento não paramétrico de transformações de fase que ocorrem durante diversos processos industriais [2], o que vem tornando plausível a otimização de parâmetros de processamento industrial de materiais com a realização de poucas experiências preliminares.

No presente trabalho relatam-se diferentes exemplos do uso do método CALPHAD para o modelamento matemático de diferentes processos térmicos e termoquímicos de aços, os quais correspondem a estudos de casos realizados no departamento de Engenharia Metalúrgica e de Materiais da Escola Politécnica da Universidade de São Paulo (PMT-EPUSP): (i) nitretação de aços de alta liga, (ii) processamento térmico de aços TRIP, (iii) obtenção de nitretos $\mathrm{CrN}$ e $\mathrm{Cr}_{2} \mathrm{~N}$ a partir de pó de cromo, (iv) tratamento térmico de solubilização de aços inoxidáveis e (v) tratamento térmico de decomposição de carbonetos em aços ferramenta. 


\section{O MÉTODO CALPHAD}

\subsection{Descrição do método}

O método CALPHAD teve inicio na década de 1970 após trabalho pioneiro de Kaufman e Bernstein [1]. Na Tabela 1 se relatam os principais marcos no desenvolvimento do CALPHAD e na Figura 1 se mostra o fluxograma geral do método.

A parte central dos algoritmos baseados no CALPHAD consiste em expressar a energia livre de Gibbs de sistemas multicomponentes, por meio de equações algébricas, em função da pressão, da temperatura e da composição química. São partes fundamentais do método os modelos numéricos que representam a estabilidade termodinâmica das diferentes estruturas cristalinas envolvidas no sistema e o procedimento numérico de minimização das expressões algébricas da energia livre de Gibbs (cálculo do equilíbrio). As equações para estimar a energia livre de Gibbs são construídas seguindo o esquema geral da termodinâmica clássica das soluções, contendo uma série de parâmetros de ajuste que podem ser otimizados em função de informações experimentais ou valores estimados por outros métodos de cálculo termodinâmico. Uma parte chave do método é o procedimento de avaliação crítica e otimização dos parâmetros termoquímicos armazenados nas bases de dados (assesment), que consiste em selecionar os dados experimentais adequados, selecionar os modelos numéricos a serem usados para expressar a energia livre de Gibss e otimizar os parâmetros de ajuste que maximizem a correspondência entre os dados experimentais e os calculados. Estas bases de dados, juntamente com um programa computacional adequado, são usadas para o cálculo de diagramas de fase e/ou de propriedades termoquímicas de sistemas multicomponentes. O que torna este método poderoso frente aos outros similares é que é possível o uso de dados provenientes de sistemas binários e/ou ternários para predizer, com alto grado de aproximação, as propriedades termoquímicas de sistemas ternários, quaternários e de ordem maior.

Tabela 1: Principais etapas de desenvolvimento do método CALPHAD [3]].

\begin{tabular}{lll}
\hline Século 19: & Gibbs - & Correlação entre equilíbrio de fases e termodinâmica clássica \\
1908: & Van Laar - & Modelamento matemático de um sistema binário \\
1929: & Hildebrand - & Conceito de soluções regulares \\
1957: & Meijering - & Análise termodinâmica do sistema Cu-Cr-Ni \\
1963: & Hume Rothery - & Equilíbrio de fases em ligas à base de Fe \\
1970: & Kaufman e Berstein - & Fundação do CALPHAD \\
1973: & & Primeiro congresso CHALPAD \\
1977: & Lukas - & Primeiro programa computacional (Luka's program) \\
1977: & & Primeiro volume da revista CALPHAD \\
& & Desenvolvimento contínuo de programas computacionais e de \\
Desde 1981: & & modelos de cálculo \\
\hline
\end{tabular}




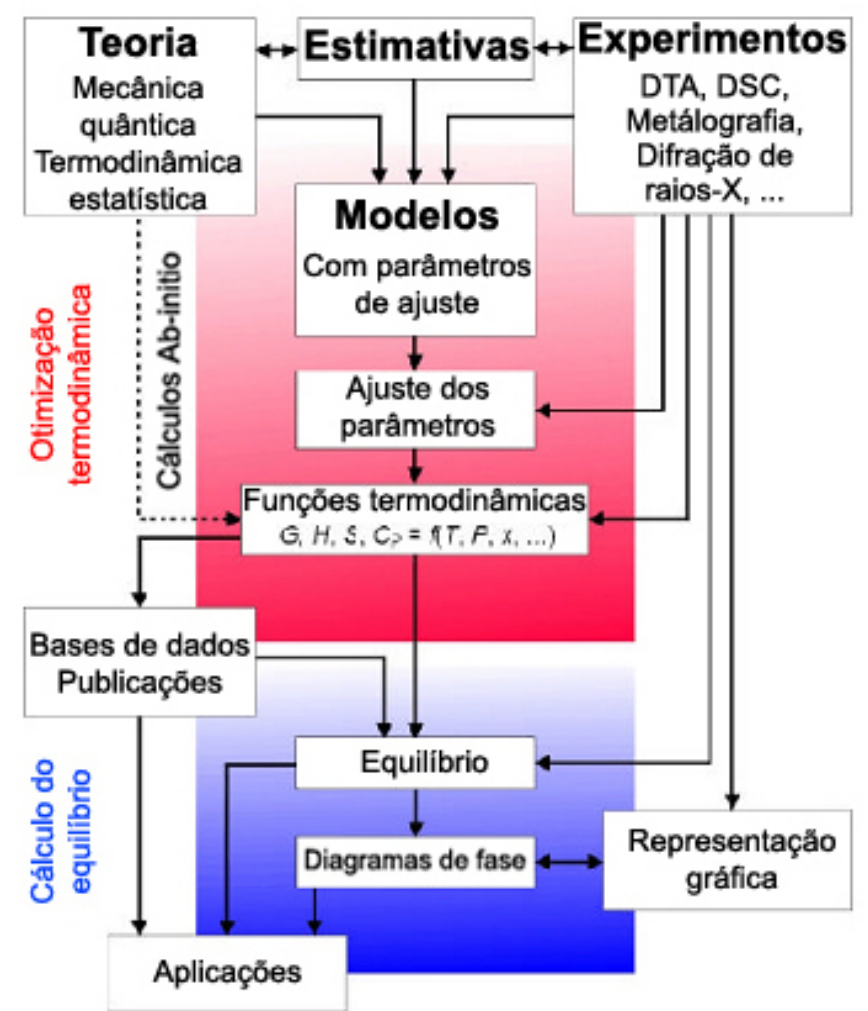

Figura 1: Fluxograma do método CALPHAD.

Tabela 2: principais programas computacionais comerciais para realizar cálculos termoquímicos usando o método CALPHAD [4].

\begin{tabular}{|c|c|}
\hline ExTerm: & $\begin{array}{l}\text { Conversão de dados entre diferentes modelos termodinâmicos, avaliação crítica de } \\
\text { dados experimentais, etc. }\end{array}$ \\
\hline MALT: & Cálculo do equilíbrio químico e construção de diagramas de potenciais químicos. \\
\hline ThermoSuit: & $\begin{array}{l}\text { Bases de dados de binários (600) e ternários (130), como também de } 5000 \\
\text { substancias. Cálculo de diagramas de equilíbrio e comparação entre dados } \\
\text { experimentais e calculados. }\end{array}$ \\
\hline PANDAT: & $\begin{array}{l}\text { Cálculo de diagramas de fase, previsão da microestrutura bruta de fusão usando o } \\
\text { modelo de Scheil. }\end{array}$ \\
\hline FactSage: & $\begin{array}{l}\text { É uma fusão do FACT e ChemSage. É usado para cálculo do equilíbrio } \\
\text { termodinâmico. Tem } 11 \text { modelos de solução diferentes, } 4400 \text { compostos e } 3400 \\
\text { substâncias puras (SGTE). }\end{array}$ \\
\hline MTDATA: & $\begin{array}{l}\text { Cálculo de diagramas de fase, e cálculo do equilíbrio termodinâmico, tem } 18 \text { bases } \\
\text { de dados. }\end{array}$ \\
\hline ThermoCalc: & $\begin{array}{l}\text { Cálculo de diagramas de fase, cálculo do equilíbrio termodinâmico, tem } 22 \text { bases de } \\
\text { dados e } 30 \text { modelos de solução diferentes. }\end{array}$ \\
\hline DICTRA: & $\begin{array}{llllll}\text { (diffusion controlled transformations) } & - & \text { simulação } & \text { numa } & \text { dimensão } & \text { de } \\
\text { transformações de fase controladas por difusão. } & & & & \end{array}$ \\
\hline
\end{tabular}

$\mathrm{Na}$ literatura (vide por exemplo [4]), observa-se uma grande quantidade de bases de dados comerciais, para diversos tipos de materiais, e diversos programas computacionais. A Tabela 2 relata os principais programas computacionais comerciais para realizar cálculos termoquímicos usando o método CALPHAD, bem como uma breve resenha das suas principais características. Destes programas, os mais usados mundialmente são o Thermocalc $^{\circledR}$ e o Dictra $^{\circledR}$. O Thermocalc ${ }^{\circledR}[\underline{5}]$ é um programa computacional, e um conjunto de bases de dados, que permite cálculos do equilíbrio termodinâmico, construção de diagramas de fase e avaliação crítica de dados termodinâmicos. O programa oferece diferentes caminhos de cálculo em função do nível do usuário, existindo hoje uma versão "amiga do usuário" que trabalha em ambiente gráfico (sistema de janelas) com a qual é possível gerar diagramas de fase e realizar alguns cálculos termodinâmicos simples. O Dictra ${ }^{\circledR}[5,6]$ é um programa computacional que permite, por meio de métodos numéricos, a resolução, numa dimensão, das equações de difusão de sistemas multicomponentes. Com esse programa é 
possível o estudo de três geometrias diferentes (placa plana infinita, cilindro infinito e esfera), o uso de várias condições de contorno e a resolução de problemas com interfaces móveis (Stefan problems). O programa tem interface com o ThermoCalc ${ }^{\circledR}$ e com uma base de dados de mobilidades atômicas de 75 elementos diferentes. Há no programa implementados sete modelos de transformações de fase: difusão em sistemas monofásicos, migração controlada por difusão de interfaces móveis, difusão em sistemas dispersos (considerando condições de equilíbrio numa microrregião contendo a fase matriz e as fases dispersas), coeficiente de difusão efetiva em sistemas multifásicos, difusão entre células de igual potencial químico, engrossamento de precipitados e crescimento cooperativo de fases lamelares.

\subsection{Modelos de cálculo}

Para o cálculo do equilíbrio termoquímico num sistema multicomponente é necessário calcular qual é a configuração do sistema que minimiza a sua energia livre Gibbs $(\mathrm{G})$ :

$$
G=\sum_{i=1}^{p} n_{i} G_{i}^{\varphi}=\text { mínimo }
$$

onde $n_{i}$ é o número de moles e $G_{1}^{\varphi}$ é a energia livre de Gibbs da fase $i$.

Assim, para fazer uma descrição termodinâmica de um sistema multicomponente é necessário construir uma função termodinâmica de $G_{i}^{\Psi+}$ para cada fase possível no sistema. O método CALPHAD utiliza uma variedade de modelos para descrever a energia livre de Gibbs das diversas fases num sistema multicomponente, em função da pressão (normalmente a dependência de $\mathrm{G}$ com a pressão não é levada em consideração), da temperatura (em geral, para temperaturas maiores a $0{ }^{\circ} \mathrm{C}$ ) e da composição química. A seguir será brevemente descrito o modelo de soluções regulares usado para descrever a energia livre de Gibbs de sistemas binários, como também de sistemas de ordem maior (ternários, quaternários, ...)

\subsubsection{Sistemas Binários.}

Assumindo que todas as posições do reticulado cristalino são equivalentes, quer dizer, há uma

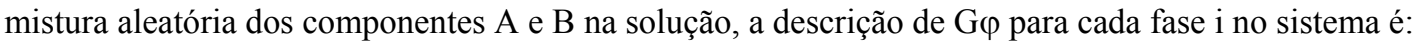

$$
G_{i}^{\varphi}=x_{A}{ }^{o} G_{A}+x_{B}{ }^{o} G_{B}-T \Delta S^{\varphi}+{ }^{E} G_{i}^{\varphi}+{ }^{m a g} G_{i}^{\varphi}
$$

onde $x_{A}$ e $x_{B}$ são as frações molares dos componentes A e B, ${ }^{\circ} G_{A}$ e ${ }^{o} G_{B}$ são as energias livres molares de A e $\mathrm{B}, T \Delta S^{\varphi}$ é a contribuição entrópica à energia livre devida às diferentes possibilidades de configuração na mistura $\mathrm{AB},{ }^{E} G_{i}^{\varphi}$ é a energia livre de excesso que representa o desvio com relação a uma solução regular e ${ }^{m a g} G_{i}^{\varphi}$ é a contribuição à energia livre de Gibbs decorrente das interações magnéticas.

A contribuição entrópica configuracional pode ser expressa como:

$$
-T \Delta S^{\varphi}=R T \sum_{i} x_{i} \ln \left(x_{i}\right)
$$

A energia livre de excesso ${ }^{E} G_{i}^{\varphi}$ é geralmente expressa como função da composição usando-se um polinômio de Redlich-Kister:

$$
\begin{aligned}
& { }^{E} G_{i}^{\varphi}=x_{A} x_{B} I_{A, B} \\
& I_{A, B}=\sum_{k=0}{ }^{k} L_{A, B}\left(x_{A}-x_{B}\right)^{k}
\end{aligned}
$$

onde o parâmetro L é um parâmetro de ajuste que representa o desvio com relação a uma solução regular. A energia livre de excesso ${ }^{m a g} G_{i}^{\varphi}$ é geralmente expressa como uma contribuição magnética à capacidade térmica da solução: 


$$
{ }^{m a g} G_{i}^{\varphi}=R T \ln (\beta+1) f(\tau), \tau=\frac{\mathrm{T}}{\mathrm{Tc}}
$$

onde $\beta$ é o número de spins de elétrons não emparelhados e $f(\tau)$ pode ser calculado como:

$$
\begin{aligned}
& f(\tau)=1-\left[\frac{79 \tau^{-1}}{140 p}+\frac{474}{497}\left(p^{-1}-1\right)\left(\frac{\tau^{3}}{6}+\frac{\tau^{9}}{135} \frac{\tau^{15}}{600}\right)\right] / A, \text { para } \tau<1 \\
& f(\tau)=-\left[\frac{\tau^{-5}}{10}+\frac{\tau^{-15}}{315} \frac{\tau^{-25}}{1500}\right] / A, \text { para } \tau>1
\end{aligned}
$$

onde $A=\left(\frac{518}{1125}\right)+\left(\frac{11692}{15975}\right)\left(p^{-1}-1\right)$ e p depende da estrutura.

\subsubsection{Sistemas Ternários e de Ordem Maior.}

Há vários métodos para extrapolar as expressões de energia livre de Gibbs dos sistemas binários para sistemas de ordem maior. No Thermocalc é usado um método desenvolvido por Muggianu, Gambino e

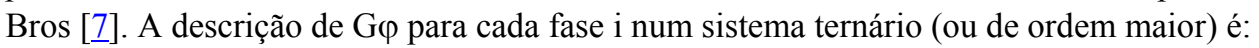

$$
G^{\varphi}=\sum_{i} x_{i}^{o} G_{i}+R T \sum_{i} x_{i} \ln \left(x_{i}\right)+\sum_{i} \sum_{j>i} x_{i} x_{j} L_{i, j}+\sum_{i} \sum_{j>i} \sum_{k>j} x_{i} x_{j} x_{k} L_{i, j, k}+\ldots
$$

onde a dependência binária da composição é calculada como acima descrito em 2.2.1, e as interações ternárias são definidas conforme proposto por Hillert []]:

$$
L_{i, j, k}=x_{i} L_{i, j, k}^{0}+x_{j} L_{i, j, k}^{1} x_{k} L_{i, j, k}^{2}
$$

O modelamento de algumas fases, como por exemplo austenita e ferrita em aços, fases intermetálicas e diversos compostos, é feito usando-se o Compound Energy Formalism (CEF) [9]], consistente em usar mais que um sub-reticulado para expressar a energia livre de Gibss da fase $i$ (por exemplo nos aços, há um sub reticulado constituído pelas posições intersticiais do reticulado e outro pelas substitucionais). Uma descrição deste formalismo desborda os limites deste trabalho, porem pode ser consultada em []].

\section{DIFUSÃO EM SISTEMAS MULTICOMPONENTES}

\subsection{Equações de Difusão para Sistemas mMulticomponentes}

A matemática da difusão trata da descrição do processo difusivo em termos da solução de uma série de equações diferenciais parabólicas chamadas equações de difusão. Quando aplicada a sistemas binários e isotrópicos, a matemática da difusão é baseada na hipótese de que a taxa de transferência de uma espécie atômica através de uma área de seção transversal unitária é proporcional ao seu gradiente de concentração [10], ou seja: (1 ${ }^{\mathrm{a}}$ lei de Fick)

$$
J_{i}=-D_{i} \frac{\partial C_{i}}{\partial X}
$$

onde $\mathrm{J}_{i}$ é taxa de transferência por unidade de área do elemento $i, \partial \mathrm{C}_{i} / \partial \mathrm{X}$ é o gradiente de concentração e $\mathrm{D}_{\mathrm{i}}$ é o coeficiente de difusão da espécie $i$.

Ao aplicarmos a lei de continuidade à Equação $11\left(\partial \mathrm{C}_{i} / \partial \mathrm{t}=\partial\left[-J_{i}\right] / \partial \mathrm{X}\right)$, e supondo que o coeficiente de difusão é constante, obtemos a equação diferencial fundamental que descreve a difusão num meio binário e isotrópico: (2a lei Fick) 


$$
\frac{\partial C_{i}}{\partial t}=D\left(\frac{\partial^{2} C_{i}}{\partial X^{2}}\right)
$$

No entanto, a maioria de materiais de engenharia possui mais que duas espécies atômicas. Em tais casos, tem-se observado que o coeficiente de difusão definido na equação 11 pode não depender só da concentração da espécie que se difunde, sendo possível que tanto a concentração quanto os gradientes de concentração de todas as espécies atômicas no material influenciem a difusão de qualquer elemento. Nesse caso é usada uma extensão da primeira lei de Fick para sistemas multicomponentes de ordem n, baseada no principio de Osanger (que postulou que cada fluxo termodinâmico pode ser relacionado linearmente com o potencial termodinâmico que o gera):

$$
J_{K}=-\sum_{i=1}^{n} L_{K i}^{\prime} \frac{\partial \mu_{i}}{\partial x}
$$

onde $\mu_{\mathrm{i}}$ é o potencial químico de cada uma das várias espécies do sistema e L' ${ }_{\mathrm{Ki}}$ é um fator de proporcionalidade que depende da mobilidade atômica de cada espécie K.

Utilizando a regra da cadeia, a Equação 13 pode ser reescrita como:

$$
J_{k}=-\sum_{i=1}^{n} L_{k i}^{\prime} \sum_{j=1}^{n} \frac{\partial \mu_{i}}{\partial c_{j}} \frac{\partial c_{j}}{\partial x}
$$

Se definirmos o termo $D_{k j}=-\sum_{i=1}^{n} L_{k i}^{\prime} \frac{\partial \mu_{i}}{\partial c_{j}}$ como difusividade reduzida, $\left(\mathrm{D}_{\mathrm{red}}\right)_{\mathrm{kj}}$, onde os termos $\partial \mu_{\mathrm{i}} / \partial \mathrm{c}_{\mathrm{j}}$ são quantidades puramente termodinâmicas (às vezes denominados fatores termodinâmicos [11]), chegamos a uma equação para sistemas multicomponentes equivalente à primeira lei de Fick:

$$
J_{k}=-\sum_{j=1}^{n}\left(D_{r e d}\right)_{k j} \frac{\partial c_{j}}{\partial x}
$$

Pode-se considerar que as difusividades reduzidas são formadas por duas partes, uma essencialmente termodinâmica e outra cinética. Observe-se que estas difusividades reduzidas incluem a possibilidade de que o gradiente de concentração de uma espécie faça outra espécie se difundir, fenômeno que foi primeiro relatado por Darken []].

\subsection{Velocidade de Migração de uma Interfase Controlada por Difusão}

Durante o crescimento de uma fase $\beta$ às expensas de uma fase $\alpha$, que segue uma cinética controlada por difusão atômica, a velocidade de migração da interfase $\alpha / \beta$ pode ser calculada resolvendo a equação 16 , para o casso em que a interfase é plana e prevalecem condições de equilíbrio na interfase:

$$
\frac{v \beta}{V_{m}^{\beta}}\left[x_{k}^{\beta}-x_{k}^{\alpha}\right]=J_{k}^{\beta}-J_{k}^{\alpha} \mathrm{k}=1,2 \ldots \mathrm{n}-1
$$

onde $v^{\beta}$ é a taxa de migração da interfase $\alpha / \beta, \mathbf{V}_{\mathbf{m}}{ }^{\beta}$ é o volume molar da fase $\beta, x_{k}^{\beta}$ e $x_{k}^{\alpha}$ são as frações molares do componente $\mathbf{k}$ na fase $\beta$ e na fase $\alpha$ a cada lado da interfase e $J_{k}^{\beta}$ e $J_{k}^{\alpha}$ são os fluxos atômicos do componente $\mathbf{k}$.

\section{ESTUDOS DE CASOS SOBRE O MODELAMENTO CALPHAD DO PROCESSAMENTO TÉRMICO E TERMOQUÍMICO DE AÇOS}

Nesta seção relatam-se diferentes exemplos do uso do método CALPHAD para o modelamento matemático de diferentes tratamentos térmicos e termoquímicos de ligas metálicas. Em todos os exemplos relatados os cálculos termodinâmicos foram realizados usando-se o programa computacional Thermocalc ${ }^{\circledR} \mathrm{e}$ a base de dados termodinâmicos TCFE, ao passo que nos exemplos onde cálculos cinéticos são envolvidos, 
as equações de difusão atômica foram resolvidas usando-se o programa computacional Dictra ${ }^{\circledR}$ e a base de dados de mobilidades atômicas Mob2.

\subsection{Nitretação de Aços de Alta Liga}

A nitretação é um tratamento termoquímico que consiste no endurecimento superficial de ligas metálicas por meio da absorção e difusão de nitrogênio. Na aproximação clássica, para modelar numericamente o processo de nitretação, considera-se o material como um sistema binário N-M, onde $\mathrm{M}$ representa a "matriz" e $\mathrm{N}$ os átomos de nitrogênio, sendo a difusão atômica do nitrogênio calculada por meio da resolução da segunda lei de Fick $[12,13]$. O possível efeito da precipitação ou dissolução de fases na difusão do nitrogênio é levado em consideração usando-se um coeficiente de difusão equivalente, que depende, ponto a ponto, do coeficiente de partição atômica entre a matriz e as novas fases precipitadas (ou dissolvidas) [13]. Considerar que o material nitretado é um sistema binário dificulta extremamente a possibilidade de calcular as variações de composição de soluto (as varias espécies atômicas que fazem parte de M) decorrentes da formação de precipitados - tanto aqueles existentes previamente em virtude da história térmica do material quanto os formados durante a própria nitretação-. Adicionalmente, em materiais com matrizes multifásicas este método de calculo torna-se muito impreciso. Assim, a aplicação da segunda lei de Fick para o modelamento matemático da nitretação de aços de alta liga leva a resultados pouco precisos, sendo necessário restringir o seu uso para o estudo dos aços ao carbono ou de baixa liga.

A natureza multicomponente e multifásica dos aços de alta liga pode ser levada mais convenientemente em consideração se, ao invés da segunda lei de Fick, é utilizada nos cálculos a equação de difusão atômica em sistemas multicomponentes (equação 13).

\subsubsection{Cinética de Nitretação a Plasma de Aços-ferramenta.}

Uma das aplicações típicas da nitretação a plasma de aços ferramenta consiste no pré-tratamento (nos chamados tratamentos dúplex) de ferramentas de corte, a ser posteriormente revestidas por deposição física de vapor (PVD) [14]. A nitretação visa aumentar a aderência dos revestimentos, o que é alcançado desde que na nitretação se evite a formação de camada de compostos.

Com o intuito de otimizar os parâmetros de nitretação a plasma dos aços-ferramenta AISI D2 $(1,53 \% \mathrm{C} ; 0,53 \% \mathrm{Mn} ; 0,89 \% \mathrm{Mo} ; 11,70 \% \mathrm{Cr} ; 0,77 \% \mathrm{~V})$ e AISI H13 $(0,40 \% \mathrm{C} ; 0,31 \% \mathrm{Mn} ; 0,89 \% \mathrm{Mo} ; 5,4 \% \mathrm{Cr}$; $0,77 \% \mathrm{~V}$ ) foi elaborado um modelo numérico CALPHAD para calcular a cinética de absorção e difusão de nitrogênio durante o tratamento termoquímico de nitretação a plasma [15]. O modelamento matemático consistiu na resolução da equação de difusão para sistemas multicomponentes (equação 13), usando-se como condição de contorno uma expressa matemática representativa do fluxo de nitrogênio na superfície do aço (equação 17).

$$
\mathrm{J}_{\mathrm{N}}^{\mathrm{X}=0}=\left[-\mathrm{D} \frac{\partial \mathrm{N}}{\partial \mathrm{X}}\right]_{\mathrm{X}=0}=\frac{\mathrm{A}}{\rho}=0,0000325 \cdot\left(\% N_{2}\right) \equiv \frac{g}{s m^{2}}
$$

onde: $\left(\% \mathrm{~N}_{2}\right)$ é a fração volumétrica de nitrogênio na mistura gasosa.

Para o cálculo da estabilidade e da composição química das diferentes fases durante a austenitização, realizada previamente à nitretação, assumiu-se que o equilíbrio termodinâmico foi atingido em todas as regiões da peça. Admitiu-se, adicionalmente, que a martensita revenida consiste de uma matriz ferrítica com precipitados finos de baixa estabilidade e alta taxa de formação e dissolução, do tipo MC e M6C. A composição química e a proporção das diferentes fases desta martensita revenida foram calculadas em função do teor de nitrogênio assumindo que prevaleçam condições de equilíbrio termodinâmico em qualquer micro-região. Adicionalmente, assumiu-se que os carbonetos grosseiros, estáveis durante a austenitização prévia, não sofram mudança durante o tratamento de nitretação, estabelecendo-se uma condição de não equilíbrio no sistema martensita revenida + precipitados grosseiros.

O modelo permitiu estabelecer não só o tempo máximo de nitretação - dadas a história térmica dos aços, a temperatura e a composição do gás de nitretação - para obter peças sem camada de compostos (Figura 2), como também a composição e as fases formadas em função dos parâmetros de nitretação e da distância à superfície nitretada (Figura 3 e 4). A microestrutura predita apresentou boa concordância com a verificada experimentalmente (Figura 2), e perfis de nitrogênio calculados representaram adequadamente os perfis de dureza medidos em amostras nitretadas (Figura 4). Os cálculos numéricos mostraram que a composição do gás, $\% \mathrm{~N}_{2}$, e o tempo de nitretação máximo para obter uma peça isenta de camada de compostos, $\mathrm{t}_{\mathrm{cr}}$, podem ser expressos por uma equação do tipo: $\% N_{2}=K\left(t_{c r}\right)^{-0,5}$ (Figura 2), onde $\mathrm{K}$ é uma constante que depende da temperatura de nitretação e da temperatura do tratamento de têmpera, realizado previamente. Embora o aço AISI D2 tenha maior teor de elementos de liga que o AISI H13, não há 
diferença significativa entre os períodos de incubação da camada de compostos calculados, quando se usam misturas gasosas com a mesma porcentagem de $\mathrm{N}_{2}$. Isso se deve ao efeito dos precipitados grosseiros formados antes da nitretação, que empobrecem em soluto a matriz do aço D2. Supor que esses precipitados não se dissolvam nos estágios iniciais da nitretação é uma boa aproximação, como se vê na Figura 2.

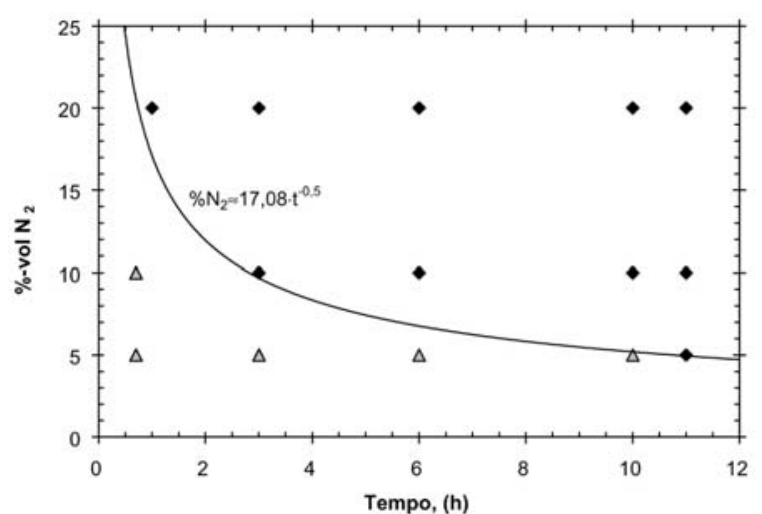

(a) AISI D2

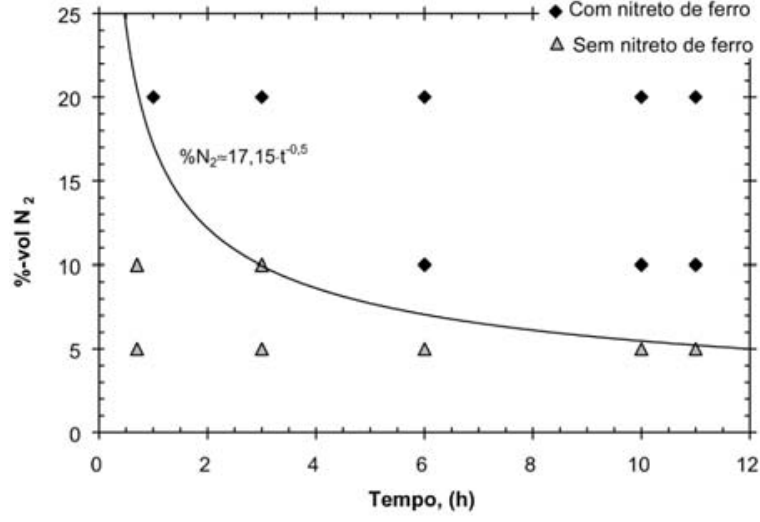

(b) AISI H13

Figura 2: Curvas de potencial limite para a nitretação a plasma a $520{ }^{\circ} \mathrm{C}$

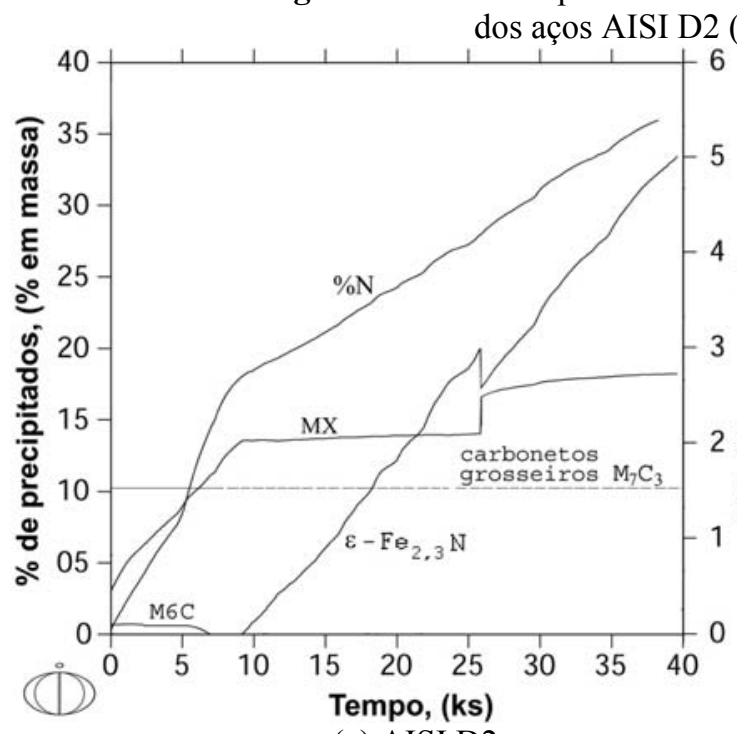

(a) AISI D2

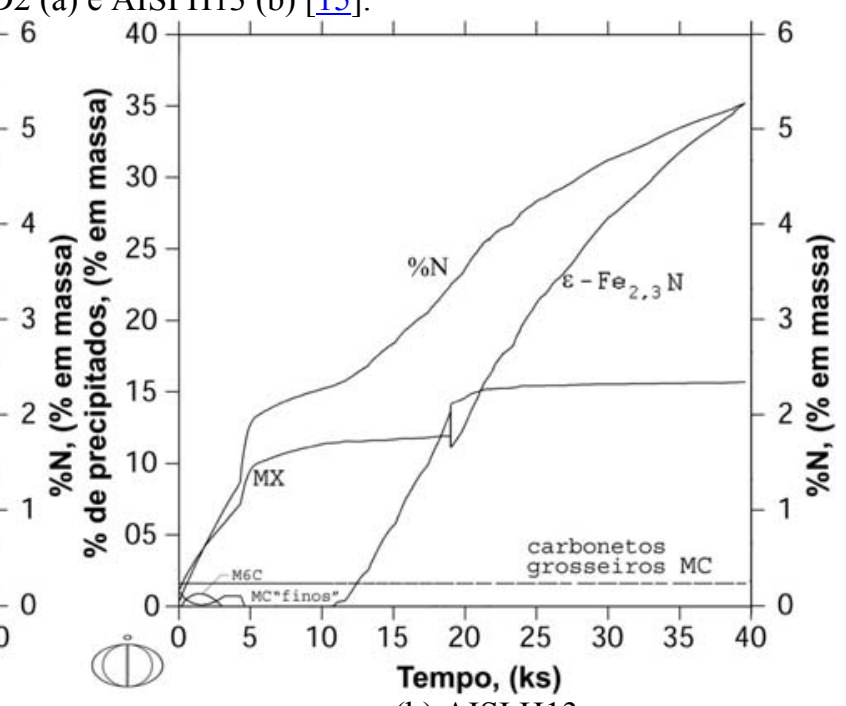

(b) AISI H13

Figura 3: Teor de nitrogênio médio e fração volumétrica das fases presentes na superfície dos aços D2 (a) e $\mathrm{H} 13$ (b) em função do tempo de nitretação, calculados para: $520{ }^{\circ} \mathrm{C}-10 \%$ vol- $\mathrm{N}_{2}$ [15]. 


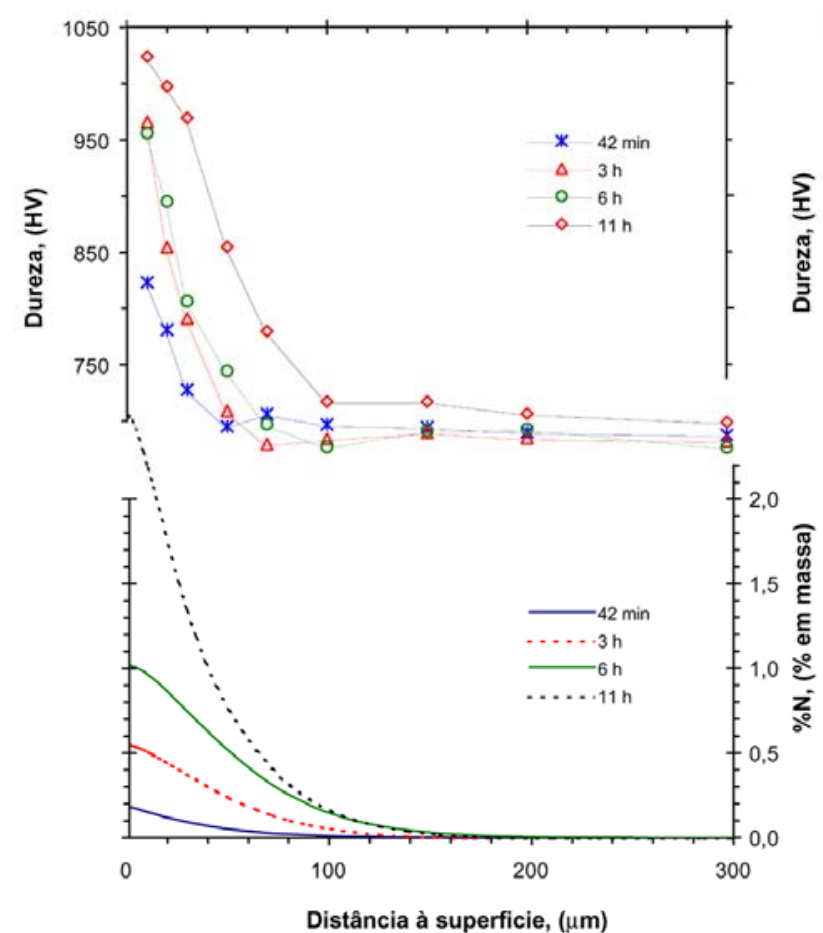

AISI D2

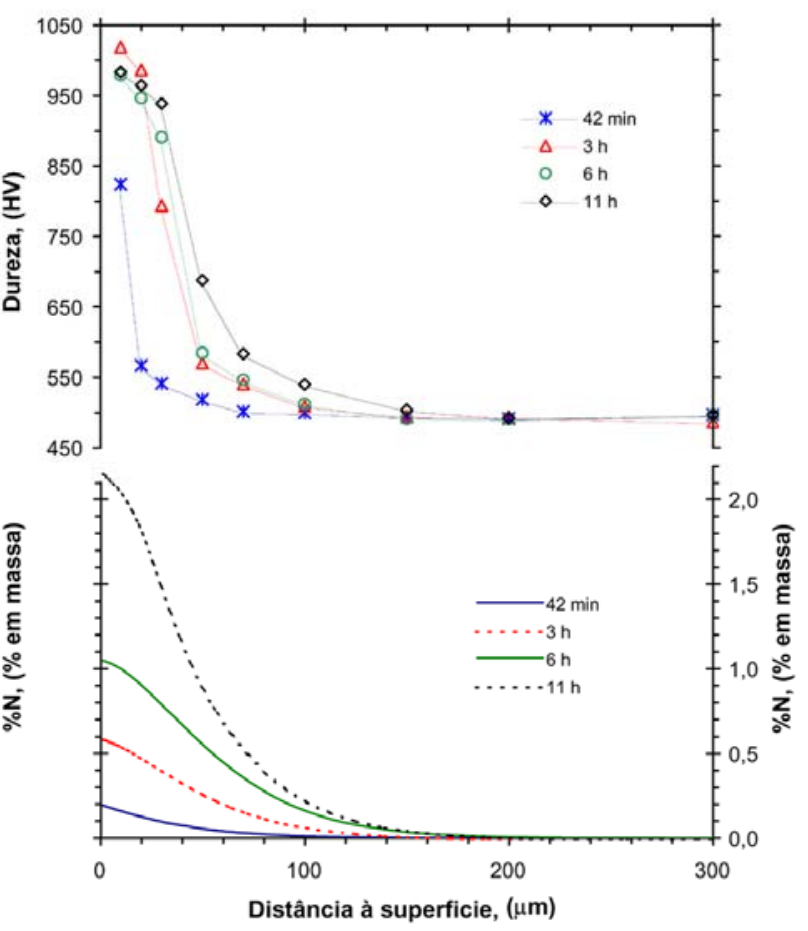

AISI H13

Figura 4: Perfis de dureza medidos e perfis de nitrogênio calculados para os aços D2 (a) e H13 (b) nitretados a $520^{\circ} \mathrm{C}$ usando-se uma mistura gasosa com $5 \%$ vol- $\mathrm{N}_{2}$ [15].

\subsubsection{Termodinâmica e Cinética dDa Nitretação Gasosa em Alta Temperatura Dde Aços Inoxidáveis}

A nitretação gasosa em alta temperatura é um tratamento termoquímico onde elevados teores de nitrogênio $(\sim 0,4-1,0 \%)$ são dissolvidos intersticialmente na região superficial de aços inoxidáveis, após os expor às atmosferas gasosas de N2, em temperaturas variando tipicamente entre 1300 e $1500 \mathrm{~K}$ (aprox. entre 1000 e 1200 oC) [16]. Desde que a precipitação de nitretos de cromo seja inibida, este tratamento permite a obtenção de peças com elevada resistência à corrosão e boa resistência ao desgaste [18]. Uma aplicação típica deste tratamento consiste na nitretação de peças de componentes que trabalham sob condições de desgaste em meios corrosivos.

Visando otimizar os parâmetros de nitretação gasosa em alta temperatura de um aço ferrítico martensítico AISI $410 \mathrm{~S}(13 \% \mathrm{Cr} ; 0,07 \% \mathrm{C} ; 0,4 \% \mathrm{Mn} ; 0,1 \% \mathrm{Ni})$ foi elaborado um modelo numérico CALPHAD para calcular a cinética de absorção e difusão de nitrogênio durante o tratamento termoquímico de nitretação gasosa em alta temperatura $[16, \underline{17}, \underline{20}]$. A absorção de nitrogênio na região superficial do aço AISI 410S promove a formação de uma camada martensítica (camada superficial austenítica em temperaturas de nitretação, que se transforma em martensita após tempera) dissolvendo a microestrutura bifásica martensitaferrita do material não nitretado (Figura 5). O algoritmo de cálculo consistiu em resolver a equação de difusão atômica para sistemas multicomponentes (equação 13) tanto na camada monofásica quanto no interior ferrítico-martensítico das peças, assumindo que prevalecem condições de equilíbrio termodinâmico em cada micro-região da peça nitretada. Como condição de contorno foi usada expressão matemática representativa do fluxo de nitrogênio na superfície do aço (equação 18). A dependência da difusão atômica na região ferrítico-martensitíca (Figura 5) com a mobilidade atômica em ambas as fases e com a partição atômica de cada elemento entre as duas fases foi levada em consideração por meio do uso do modelo de difusão em sistemas dispersos, desenvolvido por Engström et al [21] e implementado no programa computacional Dictra $^{\circledR}$. O modelo foi usado assumindo que a austenita é a fase matriz e que a ferrita é a fase dispersa. Assim, a difusividade atômica na região bifásica foi calculada multiplicando a difusividade atômica na austenita por um fator (fator labyrinth no Dictra $^{\circledR}$ ), que depende da proporção das fases austenita e ferrita. $\mathrm{O}$ fator usado foi $f^{-1.5}$, onde $f$ é a fração volumétrica da fase austenita. 


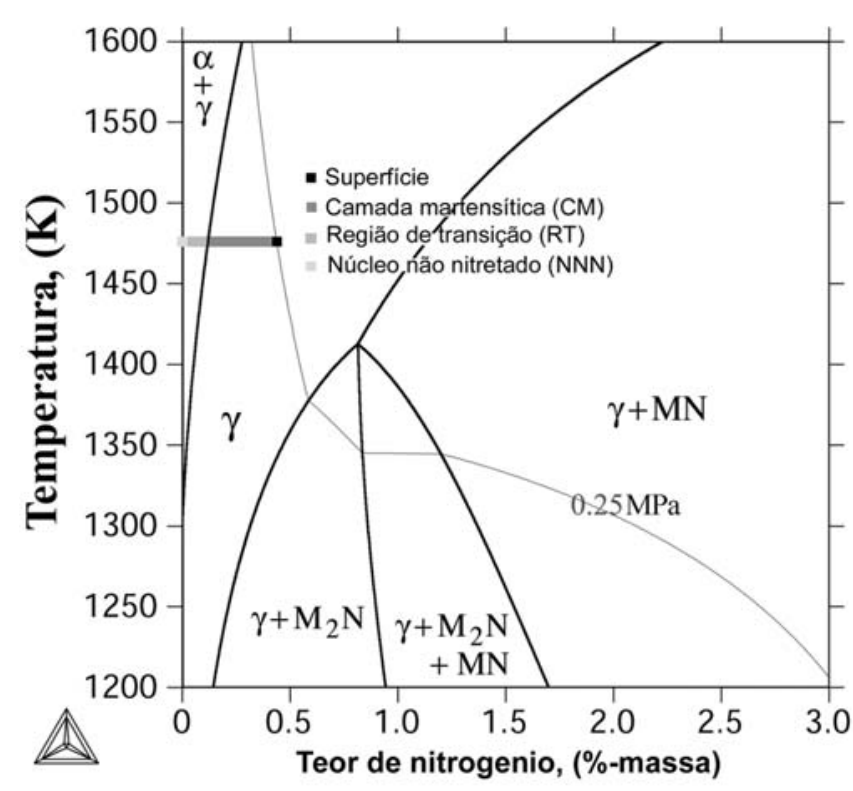

(a)

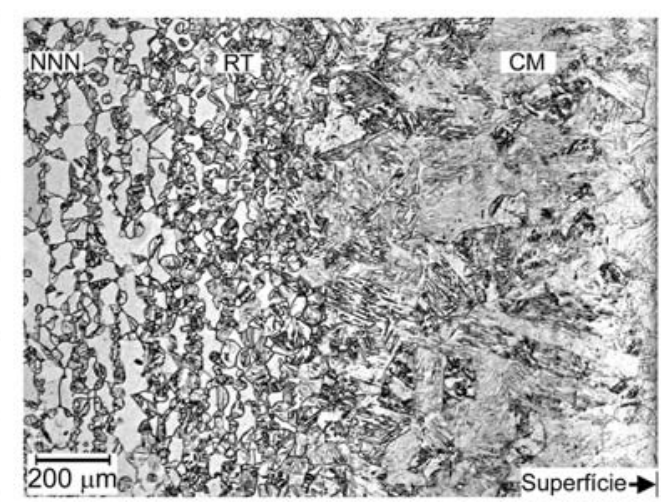

(b)

Figura 5: (a) Isopleta do diagrama de equilíbrio de um aço AISI 410S, com uma linha isobárica de 0,25 MPa pressão parcial de nitrogênio; (b) micrografia óptica da seção transversal de um aço AISI 410S nitretado a $1473 \mathrm{~K}\left(1200{ }^{\circ} \mathrm{C}\right)$ sob $0,25 \mathrm{MPa}(2,5 \mathrm{~atm})$ por $21.6 \mathrm{ks}(6 \mathrm{~h})[\underline{20}]$.

O modelamento numérico permitiu a obtenção de diagramas temperatura-pressão-tempo (TPT), que predizem o teor de nitrogênio, a microestrutura e a profundidade de camada martensítica após nitretação. A Figura 6 mostra um diagrama TPT para tratamentos de $3 \mathrm{~h}$ do aço inoxidável AISI 410S. Este diagrama foi construído superpondo: (i) diagramas calculados com o Thermocalc ${ }^{\circledR}$ que descrevem o domínio de estabilidade de fases na superfície do aço, (ii) linhas de isoconcentração de nitrogênio na superfície do aço, calculadas com o Thermocalc ${ }^{\circledR}$ para condições de equilíbrio metal-gás e (iii) linhas de isoprofundidade de camada martensítica calculadas com o Dictra ${ }^{\circledR}$ para tratamentos de $3 \mathrm{~h}$.

No diagrama TPT da Figura 6 observa-se que a temperatura de nitretação ótima está entre 1370 e $1420 \mathrm{~K}$ (entre 1100 e $1150{ }^{\circ} \mathrm{C}$ ), pois temperaturas menores retardam consideravelmente a taxa de crescimento da camada martensítica e temperaturas maiores não influenciam significativamente a mesma. A máxima pressão parcial de nitrogênio que pode ser usada sem induzir precipitação de nitretos e que, simultaneamente, leva a teores de nitrogênio variando entre 0,4 e $0,6 \%$ (pois teores menores levam a peças com dureza insuficiente e teores maiores levam a peças com excessiva quantidade de austenita retida) varia entre 0.15 e $0.4 \mathrm{MPa}$ (entre 1,5 e 4,0 atm), sendo que os menores valores de pressão se correspondem aos menores valores de temperatura do intervalo ótimo mencionado (1370 e $1420 \mathrm{~K})$.

$$
\begin{aligned}
& \mathrm{J}_{\mathrm{N}}=\alpha_{\mathrm{N}}\left(\mathrm{a}_{\mathrm{N}}^{\text {gás }}-\mathrm{a}_{\mathrm{N}}^{\text {dissolvidono aço }}\right) \\
& \alpha_{N}=0.0694 \exp \left(\frac{-23837}{T+273}\right)
\end{aligned}
$$$$
(\mathrm{mol} / \mathrm{s})
$$

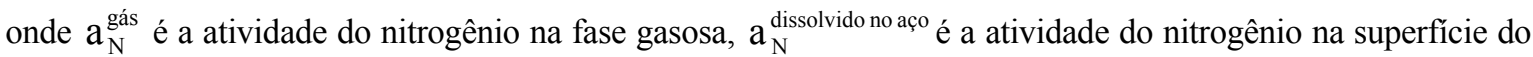
aço e $\alpha_{N}$ é o coeficiente de transferência de massa na interface metal-gás, que depende da temperatura T. 


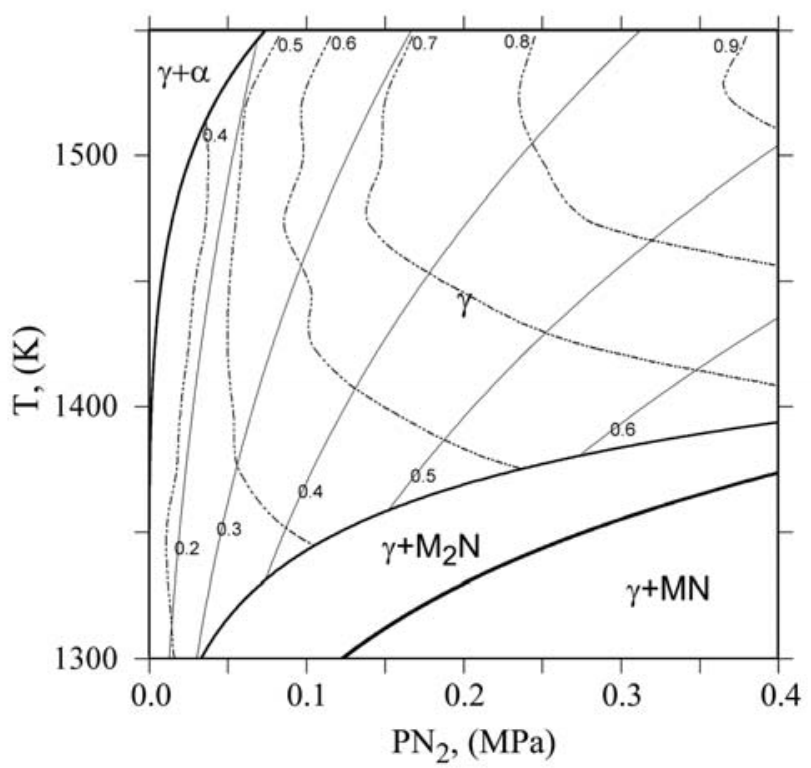

Figura 6: Diagrama TPT que relaciona os parâmetros de nitretação (temperatura e pressão parcial de nitrogênio) com a microestrutura, o teor de nitrogênio e a profundidade de camada martensítica, para tratamentos de $10.8 \mathrm{ks}(3 \mathrm{~h})$ de nitretação gasosa em alta temperatura do aço AISI 410S [20] .

\subsection{Processamento Térmico de Aços TRIP}

Os aços TRIP são aços multifásicos de baixa liga e alta resistência, susceptíveis a endurecimento por transformação martensítica, induzida por deformação, a partir de austenita retida. A elevada resistência destes aços provém do efeito conjunto de uma microestrutura multifásica - constituída por ferrita, bainita martensita e austenita retida, produto de um ciclo de tratamento descontinuo (Figura 7)- com um tamanho de grão fino produto de múltiplos ciclos de laminação e recristalização e de varias seqüências de transformações de fase-. A sua principal aplicação encontra-se na fabricação de reforços laterais para estruturas de automóveis. A proporção adequada de microconstituintes é obtida realizando um ciclo de tratamento térmico de decomposição de austenita que passa seqüencialmente pelos campos ferrítico, bainítico e martensítico (Figura 7). O controle das frações de bainita e austenita retida na microestrutura final é feito principalmente controlando a proporção e a composição da austenita remanescente após a etapa de laminado intercritica (Figura 7). Com o intuito de otimizar os parâmetros tempo-temperatura de recozimento intercritico de um aço TRIP $(0,2 \% \mathrm{C}-1,5 \% \mathrm{Mn}-1,5 \% \mathrm{Si}-0,035 \% \mathrm{Nb})$ foi elaborado um modelo numérico CALPHAD para calcular a cinética da decomposição da austenita durante o tratamento intercritico [22]. No modelo, a velocidade de migração da interfase $\alpha / \gamma$ foi calculada resolvendo a equação 16 (e conseqüentemente a equação 13), assumindo uma interfase plana e que são estabelecidas condições de equilíbrio local na interfase.

A Figura 8 mostra a cinética de decomposição da austenita a $973 \mathrm{~K}\left(700{ }^{\circ} \mathrm{C}\right)$, sendo comparados os resultados do calculo numérico com resultados experimentais obtidos por dilatometria. Adicionalmente, a Figura 9 mostra os teores de $\mathrm{Mn}, \mathrm{Si}$ e $\mathrm{C}$ nas fases austenita e ferrita para tratamentos a $973 \mathrm{~K}\left(700{ }^{\circ} \mathrm{C}\right)$. O modelo desenvolvido permitiu estimar não só a proporção de ferrita e austenita ao final do recozimento intercritico, como também a composição de ambas as fases. Observa-se que na temperatura de recozimento estudada é possível obter porcentagens de ferrita pró-eutetóide de aproximadamente $40 \%$ para tempos maiores que aproximadamente $900 \mathrm{~s}$. Adicionalmente os cálculos predizem que a precipitação de ferrite ocorre sem partição de soluto entre as fases ferrita e austenita, e que a austenita remanescente deve ter teores de carbono de aproximadamente $0,4 \%$. Uma análise mais detalhada do uso do modelo desenvolvido para otimizar a microestrutura dos aços TRIP pode ser consultada em [22]. 


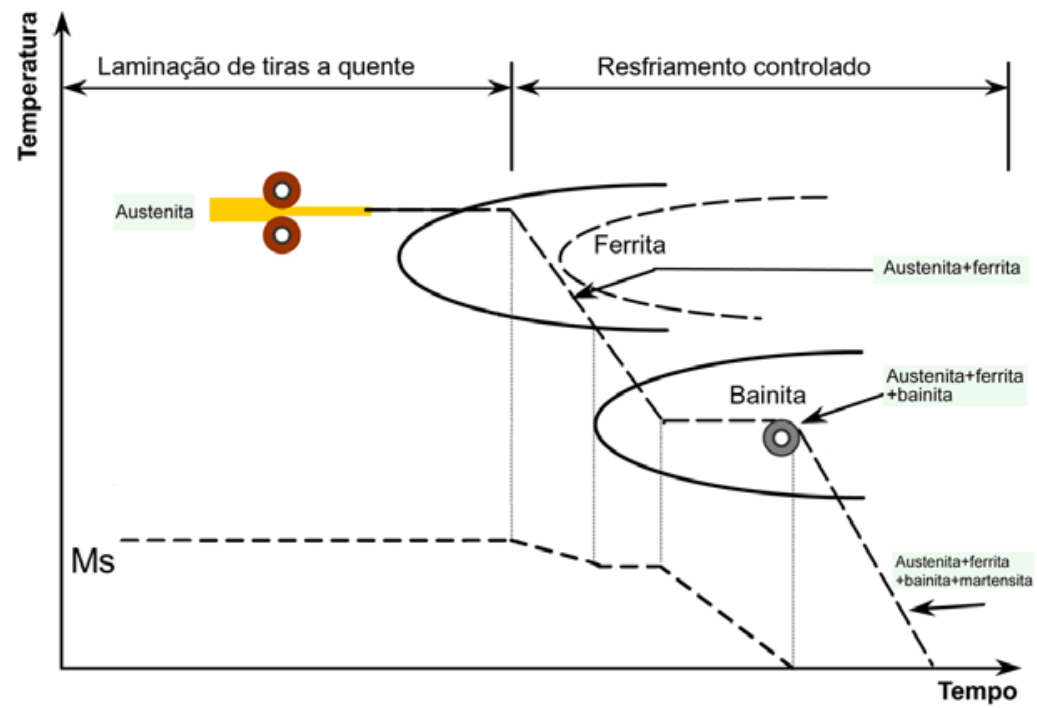

Figura 7: Esquemas de resfriamento controlado para o processamento de aços TRIP [22].

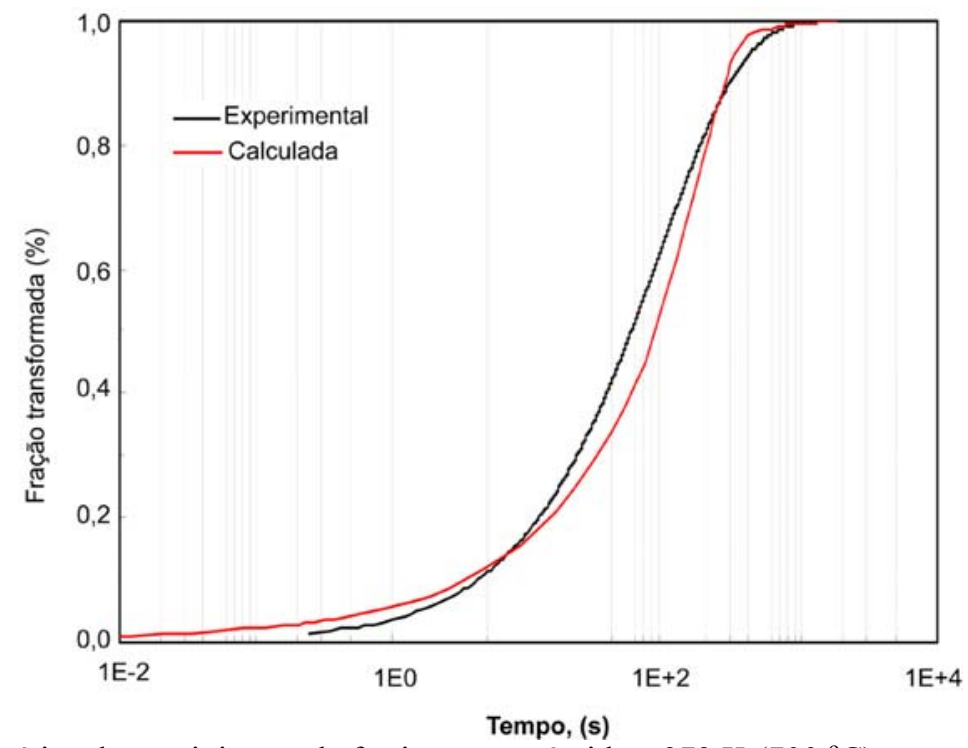

Figura 8: Cinética da precipitação de ferrita pro-eutétoide a $973 \mathrm{~K}\left(700{ }^{\circ} \mathrm{C}\right)$ num aço TRIP [22]
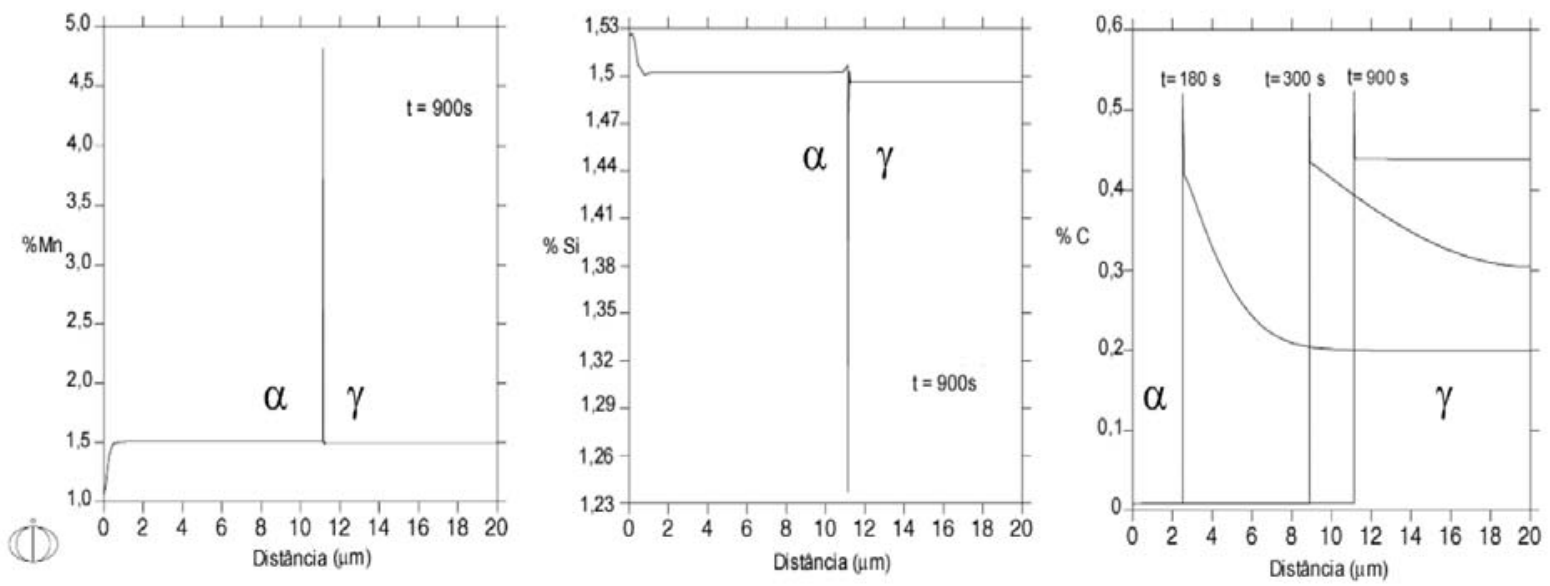

Figura 9: Teores de Mn, Si e C para um aço TRIP recozido intercriticamente a $973 \mathrm{~K}\left(700{ }^{\circ} \mathrm{C}\right)[\underline{22}]$. 


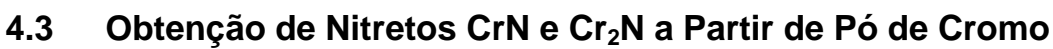

Os nitretos de cromo $\mathrm{CrN}$ e $\mathrm{Cr}_{2} \mathrm{~N}$ podem ser usados como ligantes na produção de aços inoxidáveis com alto teor de nitrogênio, tanto nos métodos que envolvem a fusão e solidificação da liga quanto no processamento por metalurgia do pó. Com o intuito de estabelecer as condições de temperatura e pressão parcial de $\mathrm{N}_{2}$ necessárias para a obtenção de cada tipo de nitreto $\left(\mathrm{CrN}\right.$ ou $\left.\mathrm{Cr}_{2} \mathrm{~N}\right)$ por meio da exposição de pó de cromo às atmosferas de nitrogênio de alta pureza, foi elaborado um diagrama de fases do sistema $\mathrm{Cr}-\mathrm{N}$, no qual são superpostas as linhas de isoatividade do nitrogênio em função da sua pressão parcial na atmosfera gasosa (Figura 10). Na Figura 10 pode-se observar que a formação do nitreto $\mathrm{Cr}_{2} \mathrm{~N}$ se da no intervalo das maiores temperaturas de tratamento termoquímico, existindo uma temperatura de transição entre a estabilidade do nitreto $\mathrm{CrN}$ e o $\mathrm{Cr}_{2} \mathrm{~N}$, que aumenta com a pressão parcial de nitrogênio. Observa-se que em função da temperatura e da pressão parcial de nitrogênio há um desvio do teor de nitrogênio do nitreto com relação à composição estequiométrica $\left(21.2 \% \mathrm{~N}\right.$ para o $\mathrm{CrN}$ e $11,9 \% \mathrm{~N}$ para $\left.\mathrm{o}_{2} \mathrm{Cr}_{2} \mathrm{~N}\right)$. No caso do nitreto $\mathrm{Cr}_{2} \mathrm{~N}$ este desvio é relativamente marcado (até $20 \%$ ) aumentando à medida que a temperatura aumenta em relação à temperatura de transição entre os nitretos $\mathrm{CrN}$ e $\mathrm{Cr} 2 \mathrm{~N}$. No entanto, o diagrama mostra, adicionalmente, que não é adequado realizar os tratamentos em temperaturas muito próximas à temperatura de transição entre $\mathrm{CrN}$ e $\mathrm{Cr} 2 \mathrm{~N}$, pois pequenas alterações na temperatura podem levar a mudanças marcadas no teor médio de nitrogênio do pó obtido.

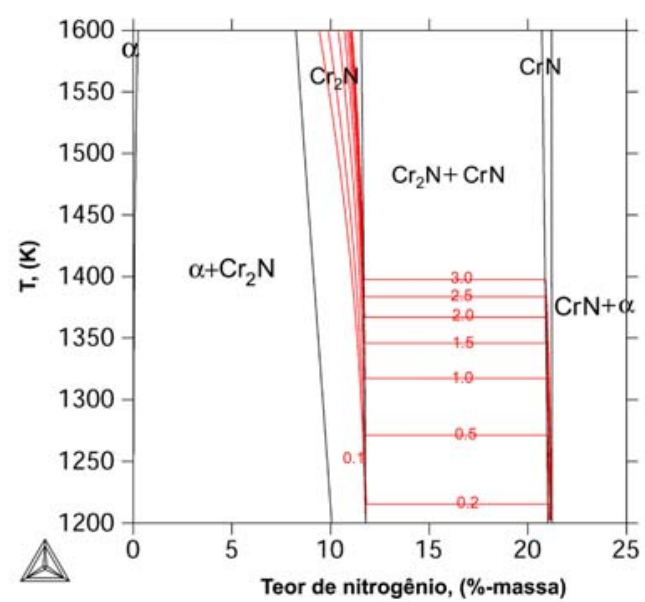

Figura 10: Diagrama de fases do sistema $\mathrm{Cr}-\mathrm{N}$, no qual são superpostas as linhas de isoatividade do nitrogênio em função da sua pressão parcial (atm) na atmosfera gasosa. (trabalho não publicado).

\subsection{Tratamento Térmico de Solubilização de Aços Inoxidáveis}

O tratamento de solubilização de aços inoxidáveis é feito visando a dissolução de carbonetos e/ou nitretos, decorrentes da historia térmica do material, e a homogeneização da composição química. Adicionalmente nos aços inoxidáveis com duas fases, como por exemplo, aços dúplex austenítico-ferríticos e aços bifásicos ferritíco-martensíticos, a solubilização visa uma adequada proporção das fases no aço, geralmente $50 \%$ de cada uma.

A Figura 11 mostra cortes isotérmicos $\mathrm{Mn}$ x C, entre 1000 e $1380{ }^{\circ} \mathrm{C}$, para auxiliar a escolha tanto de uma adequada proporção dos elementos $\mathrm{Mn}$ e $\mathrm{C}$, quanto da temperatura de tratamento de solubilização, para um aço inoxidável austenítico livre de níquel $(19 \% \mathrm{Cr}-3,5 \% \mathrm{Mo}-0,5 \% \mathrm{~N}-0,4 \% \mathrm{Si})$. Os diagramas mostram que com a composição base especificada não é possível evitar a formação de ferrita primaria durante a obtenção destes aços por fusão. No entanto há uma janela de temperaturas onde esta pode ser dissolvida durante tratamento térmico, mostrando os diagramas que o intervalo de composições de $\mathrm{Mn}$ e C que leva a uma melhor relação entre a dissolução da ferrita primaria e a precipitação de carbonetos é: 9,5$10,5 \% \mathrm{Mn}-0,15-0,17 \% \mathrm{C}$, estando a temperatura de tratamento térmico ótima ao redor de $1100{ }^{\circ} \mathrm{C}$.

A Figura 12 mostra uma isopleta $\mathrm{T} x \mathrm{~N}$, para auxiliar a escolha da temperatura de solubilização de um aço dúplex UNS S31803 $(22,5 \% \mathrm{Cr}-5,5 \% \mathrm{Ni}-2,0 \% \mathrm{Mn}-3,0 \% \mathrm{Mo}-0,02 \% \mathrm{C})$. No diagrama pode-se observar que a temperatura de solubilização adequada (aquela necessária para obter uma igual proporção das fases austenita e ferrita) é bastante sensível a pequenas mudanças no teor de nitrogênio. Para um aço com teores de nitrogênio entre 0,18 e $0,2 \%$, a temperatura de solubilização é de aproximadamente $1100{ }^{\circ} \mathrm{C}$. 

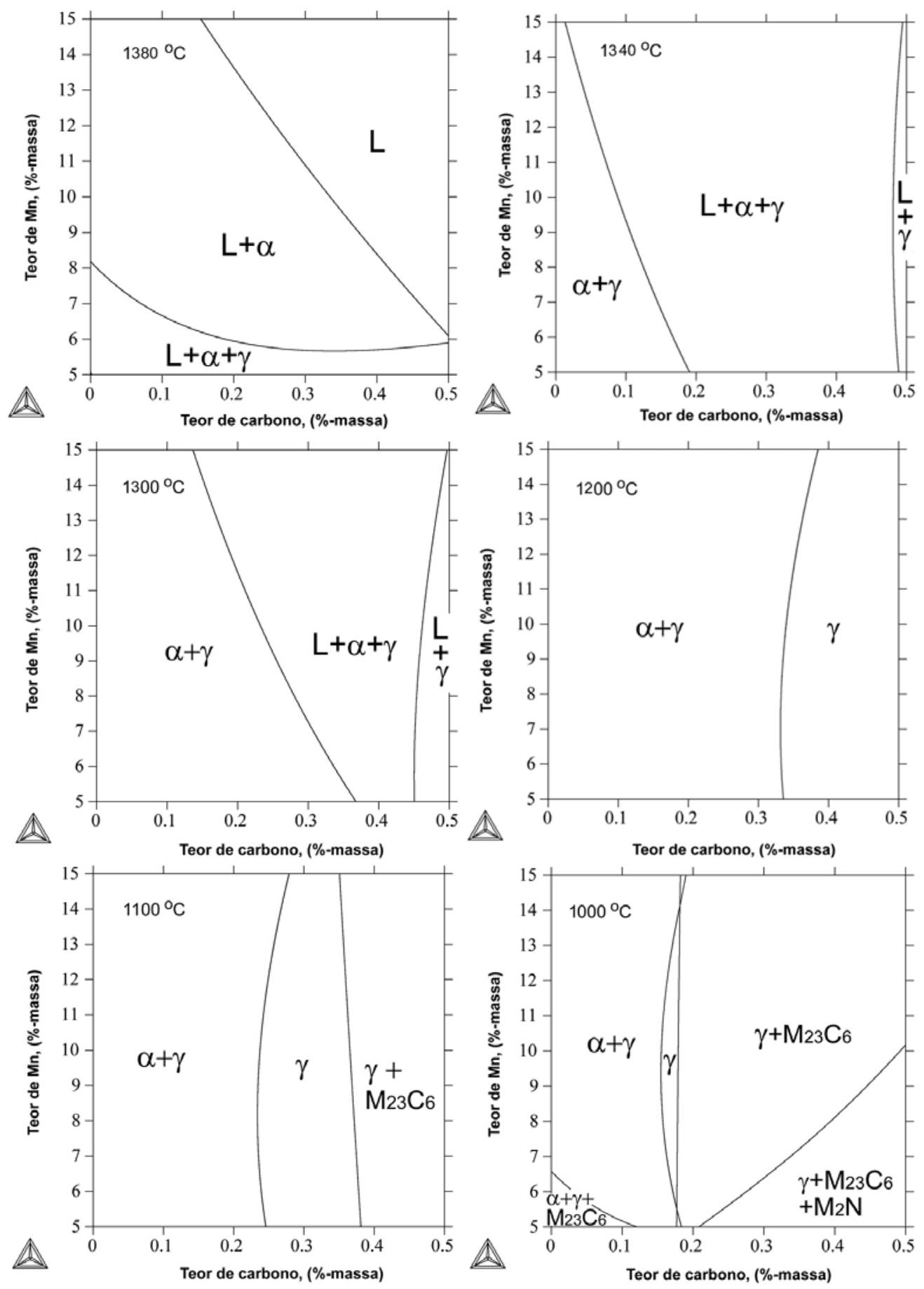

Figura 11: Cortes isotérmicos, entre 1000 e $1380^{\circ} \mathrm{C}$, para um aço inoxidável austenítico livre de níquel, $19 \% \mathrm{Cr}-3,5 \% \mathrm{Mo}-0,5 \% \mathrm{~N}-0,4 \% \mathrm{Si}$ (trabalho não publicado). 


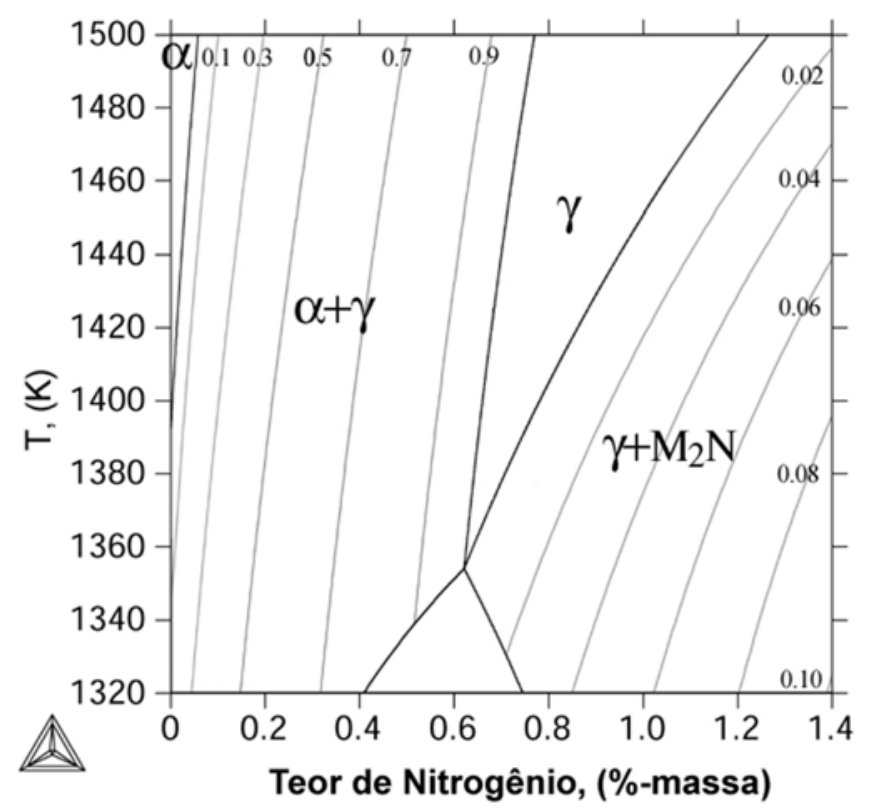

Figura 12: Isopleta de um aço inoxidável dúplex UNS S31803 $(22,5 \% \mathrm{Cr}-5,5 \% \mathrm{Ni}-2,0 \% \mathrm{Mn}-3,0 \% \mathrm{Mo}-$ $0,02 \% \mathrm{C})$. As linhas finas representam a fração das fases ferrita e $\mathrm{M}_{2} \mathrm{~N}$ [24].

\subsection{Tratamento Térmico de Decomposição de Carbonetos em Aços Ferramenta}

Durante a solidificação dos aços rápidos pode ocorrer a precipitação dos eutéticos: $\gamma+\mathrm{M} 2 \mathrm{C} ; \gamma+$ $\mathrm{M} 6 \mathrm{C}$ e $\gamma+\mathrm{MC}$, onde $\mathrm{M}$ representam os elementos substitucionais de caráter metálico presentes no aço. O tipo de carboneto eutético que precipita durante a solidificação depende tanto da composição da liga quanto da velocidade de resfriamento. No aço rápido M2 tem-se observado que velocidades de resfriamento baixas favorecem a precipitação do carboneto $\mathrm{M} 6 \mathrm{C}$ e velocidades de resfriamento moderadas e altas favorecem a precipitação do M2C. Quando o carboneto eutético precipitado durante a solidificação é o M2C, há uma forte tendência à decomposição do mesmo durante tratamento térmico.

Visando estudar a cinética de decomposição do carboneto eutético M2C durante tratamentos térmicos de decomposição do aço rápido $\mathrm{M} 2$ fundido $(0,9 \% \mathrm{C}-1,9 \% \mathrm{Cr}-5,0 \% \mathrm{Mo}-3,9 \% \mathrm{~V}-6,0 \% \mathrm{~W})$ foi elaborado um modelo numérico CALPHAD para calcular a cinética de precipitação in situ do carboneto eutético $\mathrm{M} 2 \mathrm{C}$, (M2C $+\mathrm{Fe}(\gamma) \rightarrow \mathrm{M} 6 \mathrm{C}+\mathrm{MC})$, durante tratamentos térmicos de decomposição do aço $\mathrm{M} 2$ [23]. O modelamento consistiu inicialmente em predizer a microestrutura bruta de fusão e posteriormente calcular a reação de decomposição do carboneto $\mathrm{M} 2 \mathrm{C}$, conforme o modelo esquemático mostrado na Figura 13. Na Figura 14 se mostra um diagrama TTT isotérmico que relaciona o inicio (5\%) e o fim (95\%) da reação de decomposição do carboneto $\mathrm{M} 2 \mathrm{C}$ com a temperatura e o tempo de tratamento térmico. Adicionalmente, á direta dos diagramas TTT se mostram as frações de carbonetos M6C e MC de equilíbrio, em função da temperatura, assim como o teor de carbono na austenita, para os tratamentos em que a decomposição de $\mathrm{M} 2 \mathrm{C}$ foi completada. Este diagrama visa auxiliar a escolha do tratamento térmico adequado partindo dos requerimentos de composição da austenita e de proporção de fases depois de completada a decomposição dos carbonetos M2C. Na Figura 14, se mostram, adicionalmente, os resultados da caracterização metalográfica dos carbonetos presentes em amostras tratadas termicamente entre 1050 e $1200{ }^{\circ} \mathrm{C}$, por tempos de até $2 \mathrm{~h}$. Observa-se uma correlação aceitável entre os dados experimentais e o diagrama calculado. No entanto, foi observado um desvio no que diz respeito à decomposição dos carbonetos $\mathrm{M} 2 \mathrm{C}$ grosseiros (espessuras de 1 $\mu \mathrm{m})$. Os cálculos numéricos predizem que a decomposição dos carbonetos $\mathrm{M} 2 \mathrm{C}$ grosseiros $(\sim 1 \mathrm{~mm})$ se completa entre $0,5 \mathrm{~h}$ e $4 \mathrm{~h}$, e a decomposição dos carbonetos finos $(\sim 0,4 \mathrm{~mm})$ entre $13 \mathrm{~min}$ e $1,5 \mathrm{~h}$. Adicionalmente os cálculos indicaram que as menores taxas de dissolução se apresentam no intervalo de temperaturas entre 1075 e $1125^{\circ} \mathrm{C}$.

No diagrama TTT da Figura 14 observa-se que o intervalo de temperaturas de tratamento térmico de decomposição mais adequado corresponde às temperaturas maiores que $\sim 1125{ }^{\circ} \mathrm{C}$, pois são necessários tempos de austenitização menores que duas horas e, adicionalmente, é possível obter, após tempera, matrizes martensíticas com teores de carbono maiores que $0,5 \%$. Por outro lado, temperaturas de tratamento excessivamente altas $\left(\sim 1200{ }^{\circ} \mathrm{C}\right)$ levam a matrizes com teores de carbono muito elevados (maiores que $0,65 \%$ ) e quantidades de carbonetos MC muito baixas (menor que $0,8 \%$ em massa), sendo o ganho em tempo de tratamento não tão acentuado (seriam necessários tempos de austenitização em torno de 1 h). 

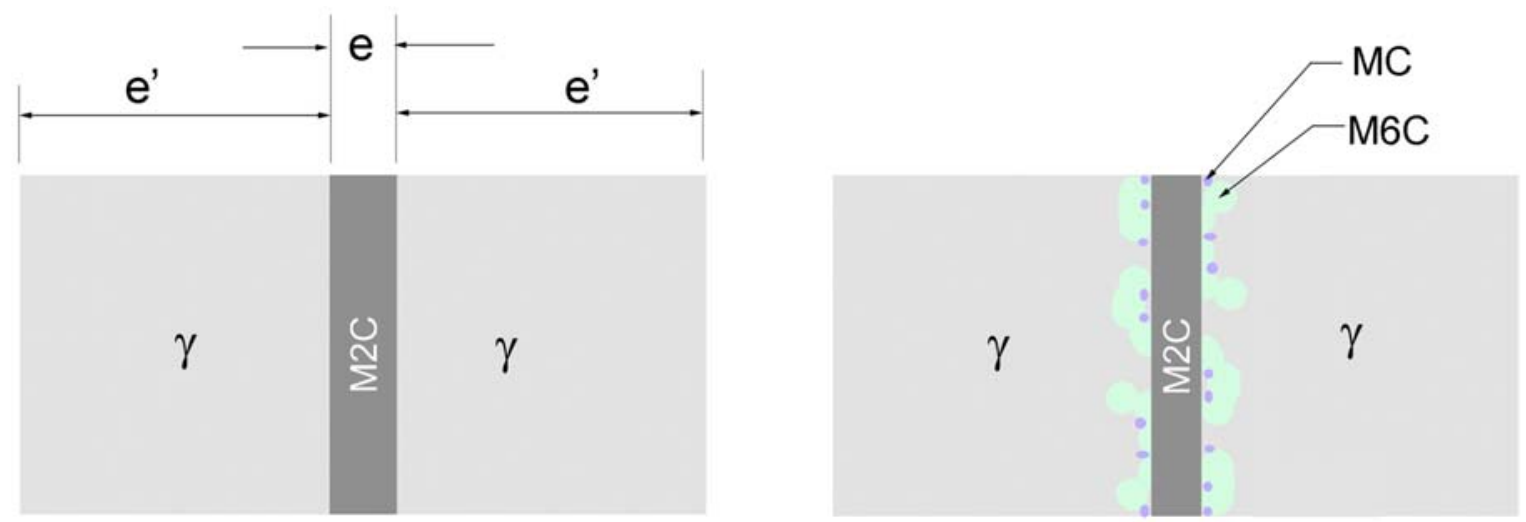

Figura 13: Esquema do modelo de cálculo usado no Dictra ${ }^{\circledR}$ para calcular a cinética da reação $\mathrm{M}_{2} \mathrm{C}+\mathrm{Fe}(\gamma) \rightarrow \mathrm{M}_{6} \mathrm{C}+\mathrm{MC}$ durante os tratamentos térmicos de decomposição de carbonetos $\mathrm{M}_{2} \mathrm{C}$ no aço rápido $\mathrm{M} 2$ fundido [23].

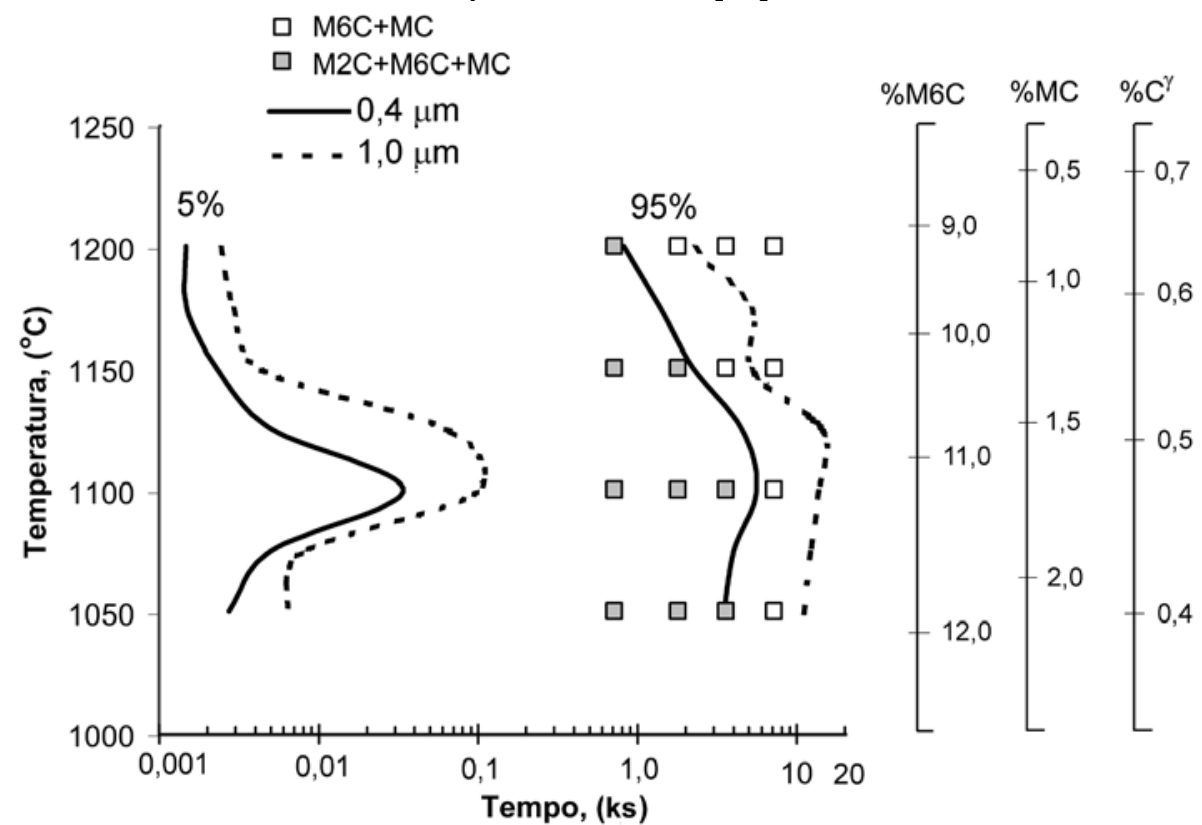

Figura 14: Diagrama TTT isotérmico da reação de decomposição do carboneto $\mathrm{M} 2 \mathrm{C}$ durante o tratamento térmico do aço rápido $\mathrm{M} 2$ fundido [23].

\section{REFERÊNCIAS BIBLIOGRÁFICAS}

[1] KAUfMAN, L, BERNSTEIN, H., Computer Calculation of Phase Diagrams with Special Reference to Refractory Metals. New York, Academic Press, 1970.

[2] KATTNER, U.R. et al, “Applications of Computational Thermodynamics”, Calphad, v.24, N. 1, pp. 5594, 2000 .

[3] ZINKEVICH, M.M., Computational Thermodynamics: Learning, Doing and Using, Max-Planck-Institut für Metallforschung, Germany, Junho 2003 (disponível em http://www.imprsam.mpg.de/summerschool2003/zinkevich.pdf)

[4] Calphad, v. 26, N. 2, pp. 141-312, 2002.

[5] ANDERSSON, J-O, HELANDER, T., HÖGLUND, L. et al., "Thermo-Calc \& DICTRA, computational tools for materials science", Calphad, v. 26, N. 2, pp. 273-312, 2002.

[6] BORGENSTAM, A., ENGSTRÖM, A., HÖGLUND, L. et al., "DICTRA, a Tool for Simulation of Diffusional Transformations in Alloys”, J. of Phase equilibria, v. 21, N. 3, pp. 269-280, 2000. 
[7] MUGGIANU, Y. M., GAMBINO, M., BROS, J. P., "Enthalpies of formation of liquid alloys bismuthgallium-tin at $723 \mathrm{k}$ - choice of an analytical representation of integral and partial thermodynamic functions of mixing for this ternary-system", J. Chim. Phys. PCB, v. 72, N. 1, pp. 83-88, 1975.

[8] HILLERT, M., "Empirical methods of predicting and representing thermodynamic properties of ternary solution phases", Calphad, v. 4, N 1, pp. 1-12, 1980.

[9] SUNDMAN, B., ÅGREN, J., "A regular solution model for phases with several components and sublattices, suitable for computer applications”, J. Phys. Chem. Solids, v. 42, N. 4, pp. 297-301, 1981.

[10] CRANK, J. The Mathematics of Diffusion. 2 ed. Oxford, Clarendon Press, 1975.

[11] PHILIBERT, J. Atom movements diffusion and mass transport in solids. França, Les Éditions de physique, 1991.

[12] ROZENDAAL, H.C.F., MITTEMEIJER, E.J., COLIJN, P.F. et al., "The development of nitrogen concentration profiles on nitriding iron”, Met. Trans. A, v. 14, N. 3, pp. 395 - 399, 1983.

[13] SUN, Y., BELL. T., “A numerical model of plasma nitriding of low alloy steels”, Mat. Sci. and Eng.- A, v. 224, N. 1-2, pp. 33-47, 1997.

[14] FRANCO, JR. A.R. Obtenção de revestimentos dúplex por nitretação a plasma e PVD-TiN em aços ferramenta AISI D2 e AISI H13. Tese de D.Sc., Universidade de São Paulo, São Paulo, SP, Brasil, 2003.

[15] FRANCO, A., GARZÓN, C. M. TSCHIPTSCHIN, A. P., “Análise numérica e experimental da cinética de nitretação a plasma de aços-ferramenta”, In: 58o congresso anual da ABM [CDROM], 3324 -33, Rio de Janeiro, RJ, Brasil, 2003.

[16] TSCHIPTSCHIN, A.P., A numerical model of plasma nitriding of low alloy steels, Materials Research, v. 5, N.3, pp.257-262, 2002.

[17] GARZÓN, C.M., TSCHIPTSCHIN, A.P., "Efeito dos parâmetros de nitretação na microestrutura de têmpera de aços $12 \% \mathrm{Cr}$ nitretados sob atmosfera de $\mathrm{N} 2 \mathrm{em}$ alta temperatura", In: $56^{\circ}$ congresso anual da ABM [CDROM], 333-42, São Paulo, SP, Brasil, 2001.

[18] BERNS, H., JUSE, R.L., BOUWMAN, J.W.et al., Solution nitriding of stainless steels - a new thermochemical heat treatments process, Heat Treat. Met. v. 27, N. 2, pp. 39-45, 2000.

[19] GAVRILJUK, V.G. BERNS, H., High Nitrogen Steels. Berlin, Springer-Verlag, 1999.

[20] GARZÓN, C.M., TSCHIPTSCHIN A.P., "Growth Kinetics of Martensitic Layers during High Temperature Gas Nitriding of a Ferritic-Martensitic Stainless Steel”. Mat. Sci. and Tech., v. 55, N. 12, pp. 915-918, 2004..

[21] ENGSTRÖM, A., HÖGLUND, L., ÅGREN, J. "Computer simulation of diffusion in multiphase systems”, Met. and Mat. Trans.- A, v. 25, N. 6, pp. 1127-1134, 1994.

[22] HURTADO, M. Estudo das transformações de fase de aços TRIP ao Si-Mn microligados com Nb. Tese de D.Sc., Universidade de São Paulo, SP, Brasil, 2003.

[23] DA SILVA, W.S., GARZÓN, C.M., GOLDENSTEIN, H. Et al., "Estudo numérico e experimental da cinética de decomposição do carboneto eutético M2C no aço rápido M2 fundido", In: 59o congresso anual da ABM [CDROM], 887-96, São Paulo, SP, Brasil, 2004.

[24] GARZÓN, C. M., TSCHIPTSCHIN A.P., "Controlling Grain Size, Nitride Precipitation and Microtexture During High Temperature Gas Nitriding of a Duplex Stainless Steel”, STEEL GRIPS journal of steel and related materials, v. 2, n. 4, pp. 659 - 665, agosto 2004. 